\title{
ROLE OF NITROSATIVE AND OXIDATIVE STRESS ON THE DEVELOPMENT OF GESTATIONAL DIABETES MELLITUS AND THEIR EFFECT IN GDM PLACENTA
}

Lỏpez-Tinoco, Cristina (1), Visiedo-Garcia Francisco (2), Mateo-Gavira, I(1), Santos-Rosendo, Celeste (2), Mateos Bernal, Rosa M (2), Segundlo-Iglesias Carmen (2), Aguilar-Diosdlado Manuel (1). (1) Department of Endocrinology, Puerta del Mar Hospital, Cảdliz, Spain (2) Investigation Unit Puerta del Mar Hospital, Cảdliz, Spain

\section{Background and aims}

The relationship between gestational diabetes mellitus [GDM] and oxidative stress is not well known and the effect of both oxidative and nitrosative stress in GDM placenta and the impact that could have on perinatal morbidity and risk of future complications is still pending to be elucidated. The aim of the study was to evaluate the relationships between maternal and placental tissue levels of markers of nitrosative and oxidative stress and antioxidants in women with GDM, which potentially may have considerable clinical implications in the pathogenesis and/or the evolution of GDM.

\section{Material and Methods:}

Pregnant women ( $n=78 ; 53$ with GDM, 25 controls), between the 24th and 29th week of gestation were enrolled. Both groups were analyzed for demographic data, perinatal and obstetrics results and the levels of the markers oxidative stress and antioxidants status were measured [measured in serum or plasma using a commercial kit (Cayman Chemical, Ann Arbor, MI, USA) $\square .7$ placenta GDM and 7 normal placenta were studied. Placental tissue levels of markers of oxidative stress and antioxidant were measured by Western Blotting techniques and Biotin-switch technique has been performed to identify S-nitrosylated protein in placental tissue.

\section{Results}

Clinics characteristics and obstetrics and perinatal results

\begin{tabular}{|l|c|c|c|}
\hline \multicolumn{1}{|c|}{ Característics } & $\begin{array}{c}\text { Cases } \\
(\mathbf{n = 5 3 )}\end{array}$ & $\begin{array}{c}\text { Controls } \\
(\mathbf{n}=\mathbf{2 5})\end{array}$ & $\mathbf{p}$ \\
\hline Maternal age; years & $31.57 \pm 4.1$ & $30.52 \pm 4.5$ & 0.3 \\
\hline SBP; $\mathrm{mmHg}$ & $116.82 \pm 16.4$ & $108.63 \pm 15.1$ & 0.005 \\
\hline DBP; $\mathrm{mmHg}$ & $68.4 \pm 10.5$ & $64,06 \pm 10.4$ & 0.02 \\
\hline pre-gestational body mass index; $\mathrm{kg} / \mathrm{m} 2$ & $27.97 \pm 5.07$ & $23.46 \pm 3.73$ & 0.001 \\
\hline Glucose; mmol/L & $5,11 \pm 0.72$ & $4.16 \pm 0,66$ & 0.0001 \\
\hline Cesarea; $\mathrm{n}(\%)$ & $24(40)$ & $6(10)$ & 0.001 \\
\hline weeks at delivery; & $39.02 \pm 1.8$ & $39.62 \pm 2.1$ & 0.09 \\
\hline Newborn weight ; $\mathrm{g}$ & $3285 \pm 500$ & $3402 \pm 457$ & 0.1 \\
\hline Macrosomia; $\mathrm{n}$ (\%) & $10(15.9)$ & $5(7.9)$ & 0.2 \\
\hline LEG; $\mathrm{n}$ (\%) & $7(11.1)$ & $3(4,8)$ & 0.3 \\
\hline
\end{tabular}

Logistic regression analysis

\begin{tabular}{|cccccc|}
\hline & B & Sig & $\operatorname{Exp}(B)$ & \multicolumn{2}{c|}{ C.I $95 \% \operatorname{Exp~(B)~}$} \\
BMI & 0,46 & 0,67 & 1,59 & 0,17 & 14,17 \\
Catalase & $-0,94$ & 0,0006 & 0,39 & 0,2 & 0,76 \\
GPX & $-117,35$ & 0,11 & 0 & 0 & $7,5 \mathrm{E}+0,12$ \\
SOD & $-40,14$ & 0,003 & 0 & 0 & 0 \\
LPO & 0,89 & 0,03 & 2,44 & 1,07 & 5,57 \\
Constant & 8,49 & 0,011 & 4892 & & \\
\hline
\end{tabular}

Levels of the markers oxidative stress and antioxidants status

\begin{tabular}{|cccc|}
\hline & $\begin{array}{c}\text { GDM } \\
\mathrm{N}=53\end{array}$ & $\begin{array}{c}\text { Controls } \\
\mathrm{N}=25\end{array}$ & $\mathrm{p}$ \\
\hline LPOs $(\mathrm{mcmol} / \mathrm{mg})$ & $3,14 \pm 1,55$ & $2,06 \pm 1,04$ & 0,001 \\
GPX(nmol/min $(\mathrm{ml})$ & $0,025 \pm 0,006$ & $0,03 \pm 0,006$ & 0,01 \\
& & & \\
GSH $(\mathrm{nmo} / \mathrm{min} / \mathrm{ml})$ & $0,0043 \pm 0,004$ & $0,0042 \pm 0,002$ & 0,7 \\
Catalase $(\mathrm{nmol} / \mathrm{min} / \mathrm{ml})$ & $2,52 \pm 1,3$ & $3,23 \pm 1,41$ & 0,006 \\
SOD $(\mathrm{U} / \mathrm{mlg})$ & $0,08 \pm 0,01$ & $0,11 \pm 0,04$ & 0,003 \\
\hline
\end{tabular}

GDM Placenta levels of LPO, SOD, GPX and catalase
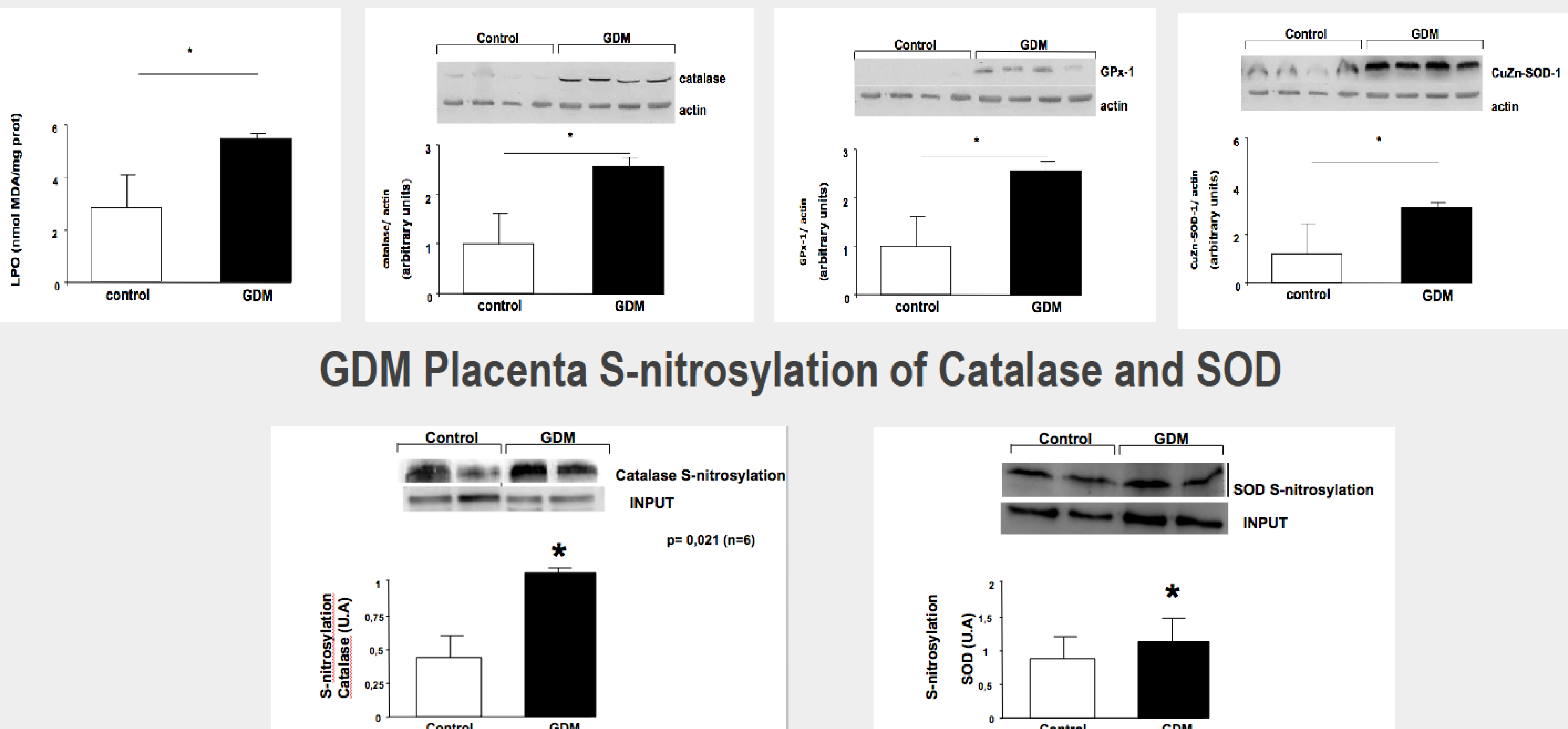

GDM Placenta S-nitrosylation of Catalase and SOD
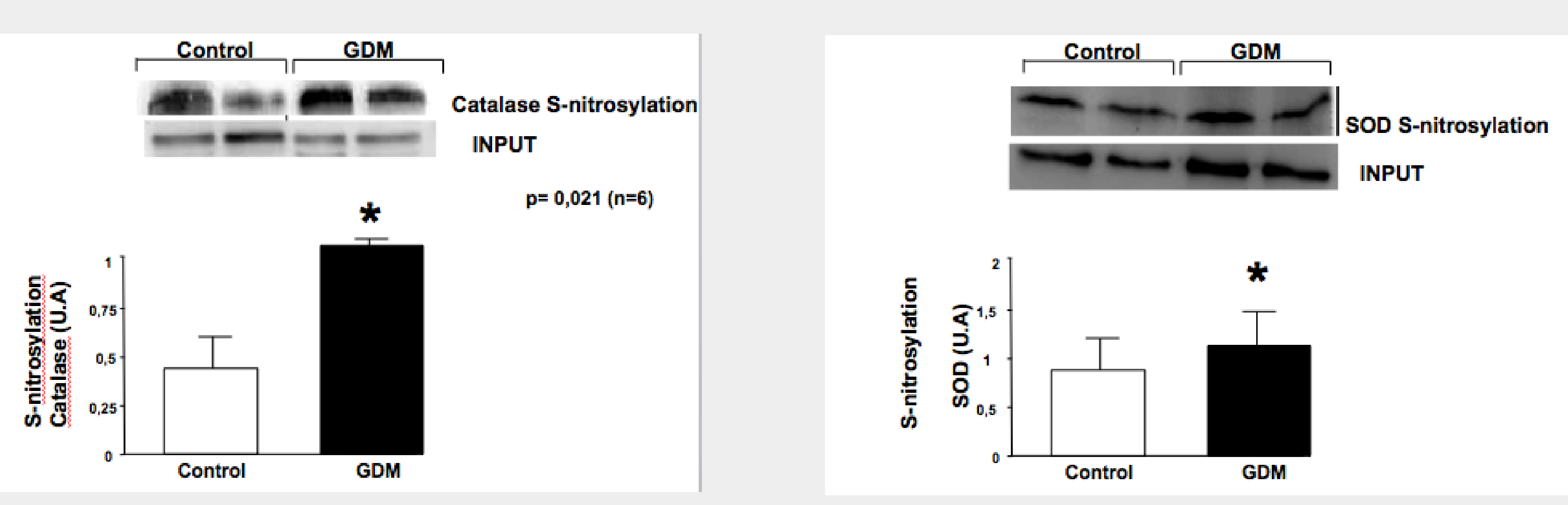

\section{Conclusions}

1. an increase in oxidative stress and a decrease in antioxidative defense can be observed in plasma of women with GDM. However, in placental tissue, elevated expression of antioxidant enzymes and an increment of their S-nitrosylation have been found which could be related with regulation of these activity.2. Results suggest that resistance to oxidative insults generated in placenta by a chronic mild oxidative/nitrosative environment could alleviate the effect of systemic elevation of ROS and RNS. The effect of both oxidative and nitrosative stress in GDM placenta and the impact that could have on perinatal morbidity should be studied more extensively . 